\title{
Honouring Caribbean Folk Cultures: A Personal Reflection
}

\author{
Glenda-Rose Layne \\ University of Trinidad and Tobago \\ nasssoma46@yahoo.com or progressive.layne7@gmail.com
}

\begin{abstract}
Drawing on my considerable knowledge of the field, this essay examines key components of the intangible cultural heritage of several Caribbean countries. It maps pictures of cultural similarities which can be traced to their roots in traditional sub-Saharan, African cultures. The article demonstrates that oral African cultural traditions derived from a rich cultural heritage are shared by the former Anglo and Francophone, Caribbean colonies. The article suggests that the cultural similarities in the folk culture, help Caribbean people to identify with each other as members of the larger African diaspora. Furthermore, the article also explores possible roles of synergy theatre, digitization and animation as mechanisms to maintain and retain the folk culture, once disseminated exclusively by our oral cultural traditions.
\end{abstract}

Keywords: Oral traditions, African legacies, socialization, communications, cultural retention, identity, and traditions

\section{Introduction}

In the Caribbean region, important factors such as, the survival of African cultural traditions introduced by the enslaved people, are visible and invisible in the region's traditional, folk culture and daily life. The survival of important aspects of sub-Saharan African, traditional culture in Anglo and Francophone Caribbean countries, indicates that the region's cultural identity is not restricted to geography and materialistic influences. The internationally known, Jamaican reggae songwriter and singer, Peter Tosh, for example once wrote, "No matter where you come from as long as you're a black man you're an African. Don't mind nationality, you've got the identity of an African." Drawing on my knowledge and experiences in the cultural field, this essay explores the view that 'who you are is more than where you were born'. The state of being which distinguishes who 'I am' is defined partly, by characteristics, over which individuals have no control such as, genetics, the parents' social and economic class and place of birth. As importantly, historical and cultural factors as well as familial and collective patterns of socialization play key roles in identity formation.

The long term impacts of European colonialism, and the legacies of the brutal slave trade and slavery which lasted for over four centuries, are some of the significant historical factors which shape the Caribbean identity. Some of the contributors to this issue explicate the specific aspects of African culture which are evident today, in explicit and subtle ways. From my observations and lived experiences, certain aspects of Caribbean culture such as communication patterns, art forms, socialization and culinary skills, often, tend to incorporate features of African traditions. Accordingly, African and European influences represent a vital part of the dynamic yet intricate tapestry that is the Caribbean culture.

Cultural and Pedagogical Inquiry, Fall 2019, 11(3), pp. 92-104

ISSN 1916-3460 @ 2019 University of Alberta

http://ejournals.library.ualberta.ca/index.php/cpi/index 
I suggest that Raymond Williams' (2002/1965) notion that culture involves "the clarification of the meanings and values implicit and explicit in a particular way of life" (Williams, 2002: 57), is applicable to the Caribbean culture. Williams further states what should be included in cultural analyses:

"Such an analysis will include historical criticism in which intellectual and imaginative works are analysed in relation to particular traditions and societies, but will also include analysis of elements in the way of life that to the followers of other definitions are not 'culture' at all: the organization of production, the structure of the family, the structure of the institutions which express or govern social relationships, the characteristics forms through which members of the society communicate." (Williams, 2002: 58)

Accordingly, by accepting Williams' views above, our communication and socialization patterns, art forms, and culinary skills, all become expressions of cultural traditions. This essay summarizes three important components of Caribbean culture, namely, communication patterns, traditional art forms and socialization patterns.

\section{Communication patterns}

Communication patterns based on African traditions can be explored verbally and nonverbally, as being part of our intangible cultural heritage. The 2003 UNESCO Convention, for example, defines the intangible cultural heritage as "the practices, representations, expressions, as well as the knowledge and skills that communities, groups and, in some cases, individuals recognise as part of their cultural heritage." It is important to note that the intangible cultural heritage of our region is not solely composed of commemorative physical structures, such as statues, monuments, museums and their collections of artefacts, but also includes the living intangible expressions, inherited from our African ancestors and passed on to the descendants who are alive today. Working within the UNESCO definition, one includes the following: oral traditions, folklore, folk dances, performing arts, social practices, rituals and festive events, knowledge and practices concerning nature and the universe, and finally, knowledge of traditional craftsmanship and techniques. Therefore folklore, and its various expressions, such as our folk dances and oral traditions must be understood and valued for their intrinsic worth as part of our intangible cultural heritage.

Although non-verbal aspects of cultural retention are considered under the umbrella of communications, for explanatory and analytical purposes, this essay highlights the African foundations and links between non-verbal aspects of communication and several of the region's cultural art forms. A few well-known phrases and non-verbal expressions, in some Caribbean countries indicate the links with West Africa. For example, the term "cooya mouth" means, a facial gesture (using pursed lips) to secretly signal to another individual and/or to draw the individual's attention. The popular non-verbal "cut eye" (also known as "bad eye") means giving someone the evil eye. And thirdly, "hands akimbo" means the placement of one's hands on one's hips to demonstrate impatience, displeasure or anger. All three examples are commonly used, since they are effective ways of communicating non-verbally. The next sections discusses the African influences in traditional dance and the accompanying music. 


\section{Art form (Traditional dance)}

Dancing is a way of life in the Caribbean. It is through dance that some aspects of our African heritage and related cultural practices are retained. Strong African dance traditions are kept alive, generation after generation, to commemorate our ancestors and to mark historical events. The dances derived from the Igbo, Koromate, Kongo, Temne, Manding, and Rada, just to name a few, are testimonies to the historical roots of the majority of Caribbean people in subSaharan Africa. Specific dances such as the Shango, Bongo, Limbo, Jonkonnu, Kumina, Dinki Mini, Cumfa, Pocomania and Shango are distinctly African in nature. Shango, for example, is a religious Yoruba dance. Evoking feelings of community, togetherness, joy sadness, grief or spirituality, the dance traditions are kept alive among different age groups in several different countries. When one sees many hybrid forms of dances (and the global community is continuously looking for new dance forms based on cultural roots), it is interesting to note that traditional dances from Africa are still prevalent in the Caribbean. (See article on the African influences in the National Dance Theatre Company, of Jamaica, in this issue, for a full discussion).

In an effort to retain some aspects of the traditional dances, syncretism of African and European influences are also visible. The processes of creating, recreating, interpreting and extrapolating from our African and European heritages, help to preserve and encourage cultural continuity. I think that the Bele dance traditions for example in the Eastern Caribbean, are excellent examples of the syncretism of both African and European cultures. It was, in a sense, the deliberate juxtaposition of the colonial, European ways of dancing with the indigenous dances of the enslaved Africans. Accordingly, our traditional dances attest to our roots, identity and cultural retention.

\section{The Bele dance and music in the Caribbean}

The Bele dance can be considered as the dance that most represents the folk culture of some of our islands. In the French and English-speaking Caribbean territories such as Dominica, St. Lucia, Martinique, Carriacou, Grenada, Trinidad and Tobago, patois/creole songs were created to which movement was added. It is clear that there were forms of borrowing and adapting as the two cultures (African and French) interacted. From my experiences, the European influence is seen in the costuming and lyrics of the songs, while the positions of the body, the sensual swaying of the hips, the varying gestures with the hands in manipulating the skirts, are attributed to the Yoruba women of Nigeria.

The movements are accompanied by a particular musical feature involving "call and response." It is a compositional technique that works in similar ways to a conversation. A "phrase" of music serves as the "call," and is "answered" by a different phrase of music. The phrases can be either vocal, instrumental, or both. With its roots in traditional African music, it is accompanied with lyrics and voice. In the dance itself, I note that there is an overwhelming presence of African style, in terms of behaviours and mannerisms that are responsible for the grace and beauty of the dance. The following section discusses the Bele Yards in some detail.

Establishment of the Bele Yards: Over the years, I note that the Bele Yards have become great fields of interest and study for researchers, both regionally and internationally. Bele Yards 
are specially assigned communal spaces where key rituals and practices, associated with the Bele traditions, are performed. On the island of Martinique for example, Bele Yards are still very active. In fact, annual festivals and conferences are held which pay respect and honour to the Bele Masters (the traditional knowledge bearers of the Bele traditions). Trinidad and Tobago was also, once the home for a number of Bele Yards. Specific rituals handed down from our African ancestors are performed at the Bele Yard in order to signal the start of the Bele Feast.

When a Bele Feast is held, Bele dancers and drummers are invited, from far and wide. The feast starts with a procession to the Bele Yard, led by the host community. The symbolic artefacts of the Bele ritual in the Bele Feast are as follows:

The Procession - in which participants carry a number of ritualistic artefacts, for example, a tray with fruits, various homemade sweets, e.g. sugar cake (a confection made with grated coconut and sugar), buns, sweet bread, and grains (e.g. black eye peas, corn, and corn meal).

The Bene Cake - is a confection made from parched Bene or sesame seeds and sugar. This cake is carried in a tray on the head of one of the more experienced dancers.

The Rum - used as a libation, a cleanser, and an appeaser to appeal to the ancestors' spirits. Rum is also used as a link between the spiritual and the physical worlds. The person with the rum usually, leads the procession, pouring rum on the ground as the procession moves forwards. (The drummers playing for the procession are normally treated with a bottle of rum for themselves).

The Calabash with flowers - are held by senior dancers in the procession.

The dancers and the dances -- The lead chantuelle determines the pace of the procession. ${ }^{1}$ The senior dancers are accompanied by the rest of the participants who are drumming, chanting and dancing in specific and relevant ways, depending on what is being celebrated. There are various styles of Bele dances which vary in rhythm.

The Pole - is placed in the centre of the Bele Yard. (It is a representation of the navel or birthright).

The Table - when the procession arrives at the Yard, after everyone is led around the Pole, all of the various artefacts are placed on the Table, and the drummers and dancers take their designated places.

The Host - opens the celebration. Then, groups are allowed to showcase varying styles of Bele dances. The elders are honoured for upholding and passing on the tradition.

The Bouquet - a bouquet of flowers is given to the chosen Queen of the Bele, at the end of the feast. Traditionally, the reigning Queen crowns the next Queen.

Types of Bele Dance: The Bele dance tradition is truly a representation of the Caribbean people. The varying styles of the Bele dance are as follows:

Congo Bele - Created in Tobago. The Congo Bele was created by the late Henry James. ${ }^{2}$ The dance speaks to prowess, versatility, strength and womanhood. The stance of the various steps emphasize the lower part of the body. The accentuated hip movements speak to the strength of the African woman as mother, partner and wife. Very typical in most dances is the competitiveness amongst the dancers; demonstrated in the versatility and style in the execution of the dance movements. Henry James indicated that the hips of the African women speak to 
their abilities to bear children and to satisfy their husbands. It was with this in mind that he understood the need to not only honour women but also to tell the story of what was significant and sacred to our fore-parents. His choreography includes some of the stylistic steps which tell graphically, the story of the African woman. She is her husband's partner. Traditionally, she usually performed back-breaking, manual work in the fields. At the same time, even while labouring on the plantation, the wife and mother carries her offspring on her back.

Gwa Bele (Grande/Grand) - A style of Bele that resembles the European quadrille. The Gwa Bele is danced by two couples. The African drums are used to punctuate the movements, while the lead chantuelles chant creole songs.

Bele Kawe (Carre) - Bele Kawe is a traditional African-Caribbean folk dance that originated from West African and Caribbean cultures. This dance tells a story of two women who are having a friendly competition for a man's attention. The first part of the dance sees the women trying to get the man's attention, while the last part of the dance, represents the warding off of any bad spirits that may be standing in the woman's way. There are many different versions of the Bele Kawe.

Bele Reel \& Jig Bele - the Bele Reel and the Jig Bele were created in the village of Pembroke, Tobago. The dances originated from other celebrations where the Reel rituals were performed. For example, in weddings, after the Reel dance takes place and the Tambrin drums (the African drums that were very small in order to be easily concealed from the colonial masters) grow cold, the drummers and dancers start the other important part of the celebration, with pulsating African and folk drums. The dancers move from the Reel dance into much celebration, to a dance style which has characteristics similar to the Bele dance. However, the steps take a form of their own. The steps reflect a Reel or Jig as well as some forms of the traditional Bele. It is out of this urge to dance and celebrate that the Bele Reel and Jig Bele were given birth. In doing so, the dances made their way into the way of life of Tobagonians and into the Bele yards. The Bele Reel and Jig Bele have become a major part of the Bele Ritual.

Kalinda Bele - Trinidad - A creative Bele with movements similar to the Kalinda dance.

Creole Bele - Dominica and Trinidad and Tobago - The Creole Bele is considered one of the earliest styles of Bele with very strong African patterns. The dance has its roots in the African mating and fertility dance rites. Although this dance is done by two dancers, only one dancer usually dances at a time, except at the very end.

Bele Kont - originated in St. Lucia and is performed at wakes. The dance combines the movements of the traditional Bele with those of the St. Lucian, Kont which is also a wake dance. Some of the movements are very similar to that of the Bongo which is danced at wakes in Trinidad and Tobago.

Bele Kourant - Mainly performed in the Francophone Caribbean countries (St. Lucia, Martinique, and Guadeloupe).

Bele-belya manmay la. - Mainly danced in the Francophone Caribbean countries.

Ma Bello - A gentle Bele which originated in Martinique. It is performed in pairs, with formations similar to the European quadrille. The influence of the French minuet in the creation of Bele can be clearly seen in this variation. This Bele dance is done mainly in celebrations and at dances. 
Bele Kouwi - This is a playful Bele, whose elements can be found in the ring games of Francophone, St. Lucia, Martinique, and Guadeloupe. It is a lot of fun for the dancers to perform. They usually dance in pairs. It is danced at all types of activities and events.

\section{Art form (Traditional music)}

Musical instruments play a significant role in the preservation of cultural traditions. Instruments and music ensemble such as the Tamboo Bamboo have been influenced greatly by African cultures. Tamboo Bamboo is a band made of a collection of bamboo stems of different sizes, weights, width and lengths. The bands are mainly rhythmic ensembles comprised of a sufficient 'mix' of sounds to achieved tonal balance. The Tamboo Bamboo ensemble (in spite of its rustic appearance), has played a crucial and important role in the development of Trinidad's steel pan (steel drums). Tamboo has been an established part of Trinidad and Tobago's music. The Tamboo Bamboo was used by African Trinidadians in stick-fights, folk dances and most importantly, at Carnival celebrations.

In the past, banned from playing the drums by the slave masters, due to its smaller size and flatter shape, the Tambrin drum (mentioned earlier), was used in order to evade being detected and punished. As importantly, the drum effectively retained its tonal quality, in spite of its smaller size. (See also, Meagan Sylvester's article for discussion). The Tambrin drum represented and invoked the same energy and spiritual manifestations associated with our social life.

\section{Art form (Folk songs and music)}

Folk songs and music portray major issues in people's daily lives, including educational beliefs, philosophy, relationships, location/neighbourhood, status, gender, experiences and wisdom, age, and economic conditions. Created by people in rural communities, the folk songs were quite simple stories. As communal activities, the origins are lost in time. Accordingly, neither the composers nor the lyricists can be easily identified, and therefore neither the music nor the lyrics can be attributed to a single, original source. The music expresses the lives of a people, the way they live, and the ways in which they relate to their families. Accordingly, the songs are about a wide range of human activities, including: marriage and the elders' advice, the influences (positive/negative) of neighbours, the obeah man's roles, the charisma and reputation of village icons and characters, the wonders of nature including the ocean and the general beliefs of a people that have been transmitted for generations. Thus, folk songs are by, for and of the people.

Historically, work songs were infinitely adaptable to tasks that demanded concerted, back-breaking, manual labour. Songs (like "Hill and Gully Rider" and "Massa the Wuk tu hard fuh me, oh") tell of a time when working class, men and women experienced adversity, exploitation and oppression. In contrast, the following extract from a song, is a joyful cry. It gives thanks that slavery has been abolished:

\section{Freedom Come Oh}

Free-Dom Come Oh, Free-Dom Come Oh,

Tan-Kie Fuh Free-Dom

Free-Dom Come Oh, Free-Dom Come Oh, Free-Dom Come Oh, 
Some songs indicated dissatisfaction with the state's legal representative. For example, the following lines tell about a dispute between a policeman Mathew, who is originally from the island of Cariacou and a local man called Bailey imprisoned by the policeman. (We suspect that the singer thinks that Bailey has been wrongly imprisoned):

Carriacou Matthew.

Car-Ria-Cou Matthew, Wha Bai-Ley Do You, Wha Bai-Ley Do You?

Wha Bai-Ley Do Mek You Put Em In Jail, Oh, Wha Bai-Ley Do Mek You Put Em In Jail?

Many sea shanties were versions of rural, land songs adapted to coastal settings. Sea shanties usually described daily life. For example, in the following extract, the first fisherman/the singer wants the second man/Johnny to wake up and go fishing. As he rouses Johnny, he tells him it is getting late: "cock in the tree ah crow," and that the other fishermen are already at the shore, launching their boats: "dem other boys already pon de shore." He also tells Johnny that he has already packed the food to eat: "de bake in the sack."

Come Leh We Go/Come Leh We Go, Fish In The Sea Fuh So/Come Leh We Go, Cock In The Tree Ah Crow.

Wake Up John-Ny And Come Leh We Go/Dem O-Ther Boys Al-Rea-Dy Pon De Shore/De Bake In The Sack, And Look De Flam-Beau.

Thus, folk songs often placed communities in front of the mirror of life. The songs recorded our history, and gave us vivid pictures of life, at that time. The next section discusses the importance of storytelling.

\section{Communications and socialization through storytelling}

Within communities throughout the Caribbean, the custom of rearing children in an extended family setting is very much alive. In fact, the community spirit created within a village is the extension of familial ties, whether by blood or by bond. In many instances, the line between blood and bond ties becomes blurred. Furthermore, the strong community culture of most villages remains to this day. Many villagers, both young and old, usually gather every day at the roadside to recount the most important positive and negative occurrences. This form of interaction often brings together the entire community. It is in these informal gatherings, whether at the roadside or at an elder's home, that life lessons are taught. Young people are warned through proverbs, e.g. "friends does carry yuh buh they don't bring yuh back!" (Your friends will encourage you to do wrong things and if problems arise they are nowhere around to help you).

Long ago, children typically, gathered outside the home of their grandparents or any other elder of the community, especially on moonlit nights, to hear stories of old sing folksongs, play games, solve riddles and share some food. Elongated shadows cast by the moonlight or Flambeaus mixed with the cool evening breezes, heightened the air of mystery as the candle flies danced about, the witnesses to the night's eventful and exciting moments. The stories were convincing and for a child growing up, the characters were real. Ladiablesse, Lagahoo, Oleg, Soucouyant, Duenne, Jack-O-Lantern, Duppy, Buckman and all the other mythical characters existed not only in one's imagination; these characters were a vital part of our existence. They 
influenced where persons went and what they did in a ritualistic manner. I remember that strange women's feet were often scrutinized for hoof-like abnormalities, and that expeditions that went beyond sunset meant you had to re-enter the house by facing in a backward manner.

At that time, for children growing up in the Caribbean, animals could really talk and Brea Anansi was a man with a top hat and a walking stick who played tricks on everyone. What was most important, however, was that the fire-side gatherings, always included some food cooked outside, on a fire with three very large stones. Whether it was roast corn, roast bake, roast breadfruit, fried fish, and sometimes a rare treat of fish broth, pacro water or crayfish, there was always some food to be shared during each session. In this informal, communal setting every individual was well fed, made comfortable and entertained while being educated by the elders.

As one digs deeper into the storytelling practices of long ago, it must be noted that this was not just a simple social gathering. It was a school without walls, a school where one learned from the experiences of the elders, a school that was designed to prepare everyone to face life. Transmitted through the generations, folktales, stories, proverbs, oratory, riddles and folk songs were used as a means of socialization and communication. However, I have noticed that the expressive, social, cultural, educational and political contexts that give meaning to traditional art forms are seldom explored in the existing research. Cultural forms of expression, are communicated, enjoyed, replicated, passed on, modified, and interpreted daily. Yet, I think that some Caribbean communities employ these traditional art forms unknowingly, as they attempt to shape and mould the behavioural and attitudinal patterns of the youth and adults.

The traditional art forms mentioned above are such an integral part of the day-to-day lifestyles of Caribbean people that I think that most of the time, our use, acceptance, reception and responses to them are unnoticed. Although many of these traditions and customs are a distinctive part of our cultural identity, of major concern is the fear of losing our invaluable, intangible cultural heritage. Currently, media imperialism fuelled by technological changes, individualism and misrepresentation, present serious threats to cultural retention. Herein lies the challenge: how do we preserve our intangible cultural assets? In the next section, I explore ways in which technology can be effectively applied to help to preserve our folk culture.

\section{Synergy Process Theatre (SPT) as a method of preserving folk culture}

During a presentation at the 2005 Conference, at the Centre for Creative and Festival Arts, at the University of The West Indies, in Trinidad and Tobago, the Dominican cultural activist, Alwin Bully discussed the importance of arts and culture in terms of the development of the self, society and region. At the same conference, Canadian educator, Larry O'Farell drawing on constructivist theories, explained the potential of arts pedagogies to develop a community of learners. Collaborative theatre or Synergy Process Theatre has its roots in the constructivist philosophy and theories of learning. Grounded in the philosophies of respected theorists such as John Dewey, Jean Piaget, Jerome Bruner and Lev Vygotsky, SPT enables learning through simulated experiences. Based on the perspective that experience is the source of knowledge, it relates to cultural norms, practices and lived experiences. Synergy Process Theatre occurs through participation in games and activities. The process focuses on the re-enactment of experiences. It emphasizes the immediate with a retrospective look at what propelled the reactions, behaviours, or emotional state. The process also gives other participants an opportunity to share in the experience by becoming a part of 'what was'.

Cultural and Pedagogical Inquiry, Fall 2019, 11(3), pp. 92-104

ISSN 1916-3460 @ 2019 University of Alberta

http://ejournals.library.ualberta.ca/index.php/cpi/index 
Synergy Process Theatre is designed to increase social skills and illustrate concepts and theories. Any topic can be explored, but the process begins from the emotional state of the student, at that moment. It allows for the freedom, creativity and exploration that are associated with learning in a natural milieu. This method is by no means new. It explores the various styles and techniques in theatre through an interactive, synergistic approach. It gives participants a chance to learn various skills through allegorical drama, stories and self-expression exercises. Skills learned range widely from communications, to leadership, to problem solving, to learning teamwork, coaching, cooperating and decision-making.

Synergy Process Theatre starts from the person's behaviour, reactions, and emotions. Students discuss where they are in the learning process, what they want to learn and how they want to develop themselves. It focuses on individual experiences, specific needs and levels of learning. I suggest that through SPT the intangible cultural heritage of a people can be accurately and seamlessly passed on from one generation to the next. In the past, our cultural heritage, including folk wisdom, taught us moral values and ethics. I think that learning our cultural heritage will continue to add intrinsic significance to the various and multiple Caribbean communities of the African diaspora.

\section{Digitization and animation of folk stories}

Increased connectivity and the expansion of new media communication technologies have changed the lives of millions of people, at a rapid pace. Today, social media communications provide instant access to a vast range of information and types of entertainment. In doing so, we understand that social media has redefined learning. For example, reliable historical and cultural data, packaged in attractive and coherent ways, can be seamlessly disseminated and absorbed by the targeted learners. I think that teaching by interlacing formal education with entertainment via social media, in order to achieve an increased understanding of the curriculum's content, can be achieved. When applied to teaching, the folk culture and our intangible cultural heritage however, care must be taken to maintain the authenticity and integrity of the cultural resources and sources. Unfortunately, the intrinsic values of our cultural treasures may be distorted or erased admittedly, unintentionally, in loose translations and/or in misinterpretations and misapplications.

Currently, digitization is another method of cultural documentation, promotion and dissemination. I suggest that it can be adopted to teach oral traditions and folk culture. In addition to being entertaining, proverbs and stories taught important ethical values, behaviours and attitudes. They included such topics as friendship, honesty, humility, discipline and good manners. Riddles were used to encourage, for example, logical thinking, improvising and problem-solving. As importantly, riddles were based on life experiences and life stages. For instance, "Riddle-ah - Riddle ah Ree, what has four legs in the morning, two in the evening and three in the night time," means the development of a human, from being a baby, through to the youthful years and maturity, and finally to old age. Oral traditions and folk culture have been handed down through the generations by the elders and storytellers. Even as methods of media communications and connectivity change, I urge that steps must be taken to assimilate our traditions into the new technologies, like digitization and animation, if we desire the long-term retention of our intangible cultural heritage. 
Take for example, the story of La Diablesse, a very pretty, well-dressed woman who wore a broad brim, fancy hat but had two different feet (one was a cow's foot and the other was a human foot). In the story, La Diablesse will lure men, in the middle of the night, to their doom. This was far more than a story of a devil woman. It taught us about deception. It is a story to help us to understand the proverb that "Everything that glitters is not gold." A second story which lends itself, very well to animation, is about Papa Bois. The old man of the forest who is known by many names, including 'Maitre bois' (master of the woods) and 'Daddy Bouchon' (hairy man). Papa Bois appears in many different forms: sometimes as a deer, sometimes hairy, and although he is very old, he is still extremely strong and muscular. He has cloven hoofs and there are leaves growing out of his beard. As the guardian of the animals and the custodians of the trees, he is known to sound a cow's horn to warn his animal friends of the approach of hunters. He doesn't tolerate either killing for killing's sake, or the wanton destruction of the forest. In his deer-like form, he leads men into the deep forest. Suddenly, he would resume his true shape and issue a stern warning. Then he vanishes, leaving the hunters either lost in the forest, and/or compelling them to pay a sizeable fine.

Imagine for argument's sake that Papa Bois is animated. He becomes the main character in a video game. According to the legend, if you should meet Papa Bois, you must be very polite. "Bon jour, vieux papa" or "Bon matin, maitre" should be your greeting. The phrases could be included in the rules of the game. Players would be rewarded or punished based on applications of the animated games' rules. I suggest that if folk stories with their characters are animated, they could reinforce values such as kindness to animals, not killing for killing's sake and the preservation and conservation of the natural environment. Some animated stories could include types of positive and negative social controls, including warnings and deterrents. I suggest that characters in our folk stories can be brought to life graphically, through digitization and animation. Using the technology, the fables are recreated, making it easier for specific values, attitudes and behaviours to be learned and hopefully practiced.

Oral tradition practitioners rely on real-life experiences. They incorporate vivid, figurative language to teach the importance of facing life with an open-mind as well as learning to be careful observers of the adults and youth in their lives. Since most of the traditional knowledge bearers usually told their stories with humour, they also taught the importance of seeing the lighter side of life. When the elders laugh at a serious issue, they tend to say: "Ole people really say teeth nah go to Heaven" or "Teeth doh laugh at nothing good." However, if they found the listeners laughing continuously at the same story, they would warn them with: "Laugh and cry ah live in the same house."

Oral traditions such as proverbs, can be successfully applied to modern challenges. For example, in 2012, the respected, University of Toronto professor and honorary, Ghanian tribal chief, George J. Sefa Dei (Nana Sefa Atweneboah I), conducted a study called "African Indigenous Proverbs and the Question of Youth Violence: Making the Case for the Use of the Teachings of Igbo of Nigeria and Kiembu of Kenya Proverbs for Youth Character and Moral Education." Dei argues that although the proverbs cannot be modernized, their interpretation is usually altered to meet the specific context and issues. (See also Dei, 2013). As importantly, proverbs provided insights into the way of life, attitudes and values of our fore-parents. Some of the Caribbean proverbs which I think indicate Caribbean values and attitudes include the following:

Cultural and Pedagogical Inquiry, Fall 2019, 11(3), pp. 92-104

ISSN 1916-3460 @ 2019 University of Alberta

http://ejournals.library.ualberta.ca/index.php/cpi/index 
- When rain falls sheep and goat have to mix. (When times are hard everybody suffers together).

- Plenty hand mek work light. (When people work together, the task becomes easier).

- Bush ha ears. (When you have to speak in confidence speak softly, because there may be someone eavesdropping).

- Beg water never boil cow skin. (It is customary to boil the skin taken from the head of the cow to make "souse." The skin is tough and takes a lot of boiling. The saying means that you cannot expect to obtain a great deal if you are forced to beg).

- Don't sit down on river rock stone and talk river. (In the rural areas people go to the river to wash their clothes and to gossip, but when you do, you should never speak ill of one relative with another).

- Where molasses is, fly must be. (Birds of a feather flock together).

- Hungry dog eat raw corn flour. (When things are hard you have to make do with what you have).

- Mouth open story jump out. (If you want to keep a secret, keep silent).

- Pickney a nyam mama, but mama na nyam pickney. (No matter what the child does, the mother will continue to love it).

- Get cage before you get a bird. (Make sure you have a home before you get married).

- No gully no dey to throw bad family. (Blood is thicker than water).

\section{Conclusion}

Regardless of language spoken, throughout the Caribbean, values such as, parental respect, love for the extended family, the care and protection of the elderly and young are significant. Such values and practices, encourage strong family bonds and highlight the importance of belonging to a community. In spite of the language differences, in the Caribbean nation states, there are striking similarities in their types of songs and oral narratives. Proverbs, folk songs and riddles express ideas, attitudes, practices, reactions and responses to similar types of situations. Grandmother, for example, usually shares the wisdom of the ancestors through her stories. She reiterates their traditional wisdom and helps to shape the society's younger generations. Accordingly, Grandmother plays an important role to disseminate, preserve and retain cultural identity and our intangible cultural heritage. Christine David's book, for example, regarding the folklore of Carriacou reinforces this point in her passionate writing about life in Carriacou: "The folk tales of the people are guides to the understanding of their past. Many present a point of view and emphasize amorally. Taken as a whole, they show the wit and philosophy of the people" (David, 1985, p. 18). Concerning folk songs, David further states that "like the stories, the folk songs reflect parables of troubles or repressions, warfare and gossip" (p. 22).

Oral traditions such as proverbs are cultural lessons that are never absent from the daily speech of the English-speaking Caribbean (e.g. in Tobago Guyana, Jamaica, Grenada, and Carriacou). In the proverbs, one finds people's ideas about life, the ideals and values they hold 
dear, and also the elements they consider supreme in the spiritual as well as the physical life. Academics and cultural practitioners such as Eastlyn McKenzie state that proverbs continue to be used in the Caribbean to: relieve tensions and conflicts, to influence behaviour, endorse points more explicitly, support arguments, and reflect the values and philosophy of the ancestors. McKenzie, a former government senator, actor and cultural philanthropist, is a preferred presenter and master of ceremonies at formal events. She is well-known for her abilities to merge traditional sayings into her presentations.

Our oral traditions are rooted in historical experiences and memories of the African continent, colonialism, the slave trade and slavery. Such traditions transmit our beliefs, culture and ethical values. They reflect how we, as a people, view ourselves and others and how we interpret the social behaviours, attitudes and values of ourselves and others. I agree that traditions are: "[a] sacred cultural heritage and part of tradition as well as a way of thinking" (Ahmed, 2005, p. 12). Our traditional knowledge bearers contributed and continue to contribute to the social and moral development of our society. They are the living foundations of our intangible, cultural heritage. The challenge now lies in preserving and passing their accumulated knowledge, wisdom and folk culture to the next generation in a high tech world without borders. A world in which its citizens (adults and youth) are all too happy, chasing the latest trends on the worldwide web.

\section{Endnotes:}

${ }^{1}$ The lead singer in the Bele dances' call and response refrain.

${ }^{2}$ Mr. Henry James was a noted dancer and choreographer. He was best known for his creation of Tobago's Congo Bele which he taught at the University of the West Indies. His love of dance and culture came from his maternal grandparents who travelled from village to village dancing. In 1992, he created a Congo Bele Dance for the National Dance Theatre Company of Trinidad and Tobago's premier performance for Carifiesta V. His contribution to the culture of Trinidad and Tobago's dance landscape will not be forgotten. 


\section{References}

Ahmed, S. (2005). Educational and Social Values expressed by Proverbs in two Cultures: Knowledge and Use of Proverbs in Sudan and England. Berlin: University of Berlin.

Bonifácio, T. (2015). Proverbs as a language of Sages in African Culture. Maryknoll Institute of African Studies of St. Mary's University of Minnesota and Tangaza University College, Niarobi, Kenya.

David, C. (1985). Folklore of Carriacou. University of Texas. Digitized 21 Sept., 2007.

Dei, G. J. S. (2013). African Indigenous Proverbs and the Institutional and Pedagogical Relevance for Youth Education. Lessons from Kiembu of Kenya and Igbo of Africa. (Available online).

Gibbons, D. L. (Ed.). (2005). Arts Education for Societies in Crisis. Port of Spain: Centre for Creative and Festival Arts.

Moore-Miggins, D. (2007). The Caribbean Proverbs That Raised Us. Denver: Outskirts Press, Inc.

Roberts, P. A. (1997). From Oral to Literate Culture: Colonial experience in the English West Indies. Kingston: The University of the West Indies Press.

Roberts, P. A. (1988). West Indian and Their Language. Cambridge: Cambridge University Press.

Tosh P. (n.d.). https://genius.com/Peter-tosh-african-lyrics

UNESCO. (2003). https://ich.unesco.org/en/convention

Williams, R. (1965/1961). The Long Revolution. Harmondsworth: Penguin: OCLC 876423987.

Winer, L. (2009). Dictionary of the English/Creole of Trinidad \&Tobago. Montreal \& Kingston: McGill - Queen's University Press. 